\title{
Author's reply: Comment on: Professionalism in medical practice
}

Singapore Med J 2021; 62(10): 559 https://doi.org/10.11622/smedj.2021203

Dear Sir,

In the editorial 'Professionalism in Medical Practice', I highlighted the importance of examining the entire healthcare ecosystem when addressing the issue of medical professionalism. One cannot just focus on the lapses of the individual but must also consider the larger healthcare environment, so that gaps in the system are corrected. ${ }^{(1)}$ I welcome the author's follow-up letter, which commented on how the organisation of health systems may impose psychological strain on individuals and result in errors in professionalism. ${ }^{(2)}$ The letter highlighted the problem of overworked healthcare professionals. Medical errors may arise owing to burnout or concentration lapses. This is a part of systemic issues alluded to in the editorial that must be identified and addressed. In such instances, addressing the root causes of overwork, having a system of peer support and providing timely appropriate psychological support are all very important measures.

Yours sincerely,

Tiing Leong Ang $^{1,2}$

${ }^{1}$ Department of Gastroenterology and Hepatology, Changi General Hospital, ${ }^{2}$ Medicine Academic Clinical Programme, SingHealth Duke-NUS Academic Medical Centre, Singapore. ang.tiing.leong@singhealth.com.sg

\section{References}

1. Ang TL. Professionalism in medical practice. Singapore Med J 2021; 62:107-8.

2. Kandola AK. Comment on: Professionalism in medical practice. Singapore Med J 2021; 62:559. 